\title{
Dinâmica dos marcadores laboratoriais em crianças vítimas de queimaduras
}

\author{
Dynamics of laboratory markers in children victims of burns
}

Dinámica de los marcadores de laboratorio en niños víctimas de quemaduras

Carlos Matheus Pierson Colares ${ }^{1 *}$, Gabriela Maria Lara de Paulo1, Mykaella Cristina Araújo Margarida², Ana Caroliny da Silva ${ }^{1}$, Lais Lara Silva Xavier ${ }^{1}$, Thainara Lorraine Costa e Silva Pereira ${ }^{1}$, Isabela Leal Moreira $^{1}$, Erilane Soares da Silva ${ }^{1}$, Thais Cardoso do Nascimento², Lorena Morena Rosa Melchior ${ }^{2}$.

\section{RESUMO}

Objetivo: Analisar o perfil clínico-epidemiológico de crianças vítimas de queimaduras e a dinâmica dos marcadores laboratoriais. Métodos: Pesquisa transversal, retrospectiva, analítica, analisando prontuários eletrônicos de 263 crianças vítimas de queimaduras atendidas em um hospital de urgências do centro-oeste brasileiro no período de julho de 2015 a julho de 2019. Resultados: A média de idade foi de 3,7 anos, predominantemente vítimas de escaldaduras em tronco e em membros superiores, sendo mais frequente, médio e grandes queimados. Exames laboratoriais indicam relação estatisticamente significativa entre extensão da queimadura e menores valores na série vermelha, leucocitose com tendência a desvio a esquerda, distúrbios eletrolíticos, baixos valores de albumina e altos valores de mediadores inflamatórios como a Proteína C-Reativa. O perfil clínico-epidemiológico destas crianças possui relação estatisticamente significativa com os exames laboratoriais. Conclusão: Foram identificadas as diversas trajetórias da evolução da doença, auxiliando a equipe na predição dos eventos que sucedem a internação da criança queimada e sua evolução, tanto clínica como laboratorial, subsidiando a criação de protocolos de atendimento e de condutas.

Palavras-chave: Pediatria, Crianças, Queimaduras, Exames laboratoriais, Grandes queimados.

\begin{abstract}
Objective: To analyze the clinical-epidemiological profile of children victims of burns and the dynamics of laboratory markers. Methods: Cross-sectional, retrospective, analytical research, analyzing electronic medical records of 263 burn victims treated at an emergency hospital in the Brazilian Midwest from July 2015 to July 2019. Results: The mean age was 3, 7 years old, predominantly victims of scalds on the trunk and upper limbs, being more frequent, medium and major burns. Laboratory tests indicate a statistically significant relationship between burn extension and lower values in the red series, leukocytosis with a tendency to shift to the left, electrolyte disturbances, low albumin values and high values of inflammatory mediators such as CReactive Protein. The clinical-epidemiological profile of these children has a statistically significant relationship with laboratory tests. Conclusion: The different trajectories of the disease evolution were identified, helping the team to predict the events that follow the hospitalization of the burnt child and its evolution, both clinical and laboratory, supporting the creation of care and conduct protocols.
\end{abstract}

Keywords: Pediatrics, Children, Burns, Laboratory tests, Major burns.

\footnotetext{
${ }^{1}$ Secretaria de Estado de Saúde de Goiás (SES-GO), Goiânia - GO. *E-mail: cmpc17@gmail.com

2 Universidade Federal de Goiás (UFG), Goiânia - GO.
} 


\section{RESUMEN}

Objetivo: Analizar el perfil clínico-epidemiológico de los niños víctimas de quemaduras y la dinámica de los marcadores de laboratorio. Métodos: Investigación transversal, retrospectiva, analítica, analizando historias clínicas electrónicas de 263 víctimas de quemaduras atendidas en un hospital de emergencia en el Medio Oeste brasileño desde julio de 2015 a julio de 2019. Resultados: La edad promedio fue de 3, 7 años, predominantemente víctimas de escaldaduras en el tronco y miembros superiores, siendo más frecuentes las quemaduras medianas y mayores. Las pruebas de laboratorio indican una relación estadísticamente significativa entre la extensión de la quemadura y valores más bajos en la serie roja, leucocitosis con tendencia a desplazarse hacia la izquierda, alteraciones electrolíticas, valores bajos de albúmina y valores altos de mediadores inflamatorios como C- Proteína reactiva. El perfil clínico-epidemiológico de estos niños tiene una relación estadísticamente significativa con las pruebas de laboratorio. Conclusión: Se identificaron las diferentes trayectorias de la evolución de la enfermedad, ayudando al equipo a predecir los eventos que siguen a la hospitalización del niño quemado y su evolución, tanto clínica como de laboratorio, apoyando la creación de protocolos de atención y conducta.

Palabras clave: Pediatría, Niños, Quemaduras, Pruebas de laboratorio, Quemaduras mayores.

\section{INTRODUÇÃO}

Queimaduras são importantes causas de trauma em crianças, principalmente em lactentes e préescolares, que resultam em morbimortalidade significativa mundialmente (BARCELLOS LG, et al., 2016; FERNANDES FMF, et al., 2012; LEE CJ, et al., 2016; MILLIAN LC, et al., 2012; MORAIS PS, et al., 2014; SANTANA ME, et al., 2018). Apesar de estudos evidenciarem subnotificações dos casos de queimaduras, estima-se que no Brasil ocorrem cerca de um milhão de acidentes por ano, sendo que 200.000 indivíduos vão procurar atendimento à saúde (BARCELLOS LG, et al., 2016; FERNANDES FMF, et al., 2012; LEE CJ, et al., 2016; MORAIS PS, et al., 2014; SANTANA ME, et al., 2018). Mundialmente, esse número eleva-se para cerca de 24 milhões de pessoas vítimas de queimadura ao ano (DUTRA JPS, et al., 2017).

As queimaduras são classificadas pelo grau de comprometimento das camadas da pele, sendo classificadas como queimaduras de primeiro, segundo e terceiro grau. As queimaduras de primeiro grau acometem a epiderme em sua parcialidade. Já a de segundo grau, compromete a epiderme e penetra na derme, porém não a ultrapassa, há presença de bolhas. A de terceiro grau acomete todas as camadas da pele, a derme como um todo, chegando ao tecido subcutâneo, músculos e ossos (GREENHALGH DG, 2019; SU L, et al., 2019; STROBEL AM e FEY R, 2018).

Além da classificação do grau de comprometimento tecidual ocasionado pela queimadura, é realizada a classificação quanto à extensão da queimadura, ou seja, a Superfície Corporal Queimada (SCQ). Esta está diretamente ligada à mortalidade, ou seja, quanto maior a porcentagem de SCQ, maior será a probabilidade de morte (KHONGWAR D, et al., 2016).

A utilização de exames laboratoriais traz informações importantes a respeito da vítima de queimadura e são marcadores fundamentais para acompanhar o prognóstico durante a internação. É comum que esta dinâmica laboratorial se altere continuamente durante a internação, já que após a queimadura há uma demanda metabólica alterada, levando também a alterações de níveis imunológicos e de eletrólitos (TIRYAKI C e HAKSAL MC, 2019).

No Japão, foi conduzida uma pesquisa com pacientes adultos vítimas de queimadura e encontraram alterações importantes no hemograma, coagulograma e leucograma, identificando assim o impacto no prognóstico a longo prazo e além disso levantou marcadores laboratoriais preditores de mortalidade (OSUKA A, et al., 2019).

É de grande relevância científica o conhecimento de alterações de marcadores laboratoriais para auxílio na predição de mortalidade, acompanhamento de prognóstico e ainda prever futuras complicações. 
Atualmente há poucos dados na literatura sobre essa temática, principalmente em crianças. Diante disso o objetivo do foi analisar o perfil clínico-epidemiológico de crianças vítimas de queimaduras e a dinâmica dos marcadores laboratoriais.

\section{MÉTODOS}

Trata-se de um estudo do tipo epidemiológico, transversal, retrospectivo, de abordagem quantitativa, analítico. Realizado de janeiro a dezembro de 2020, em um hospital de urgência e emergência do centrooeste brasileiro, com foco em traumatologia, queimaduras e medicina intensiva.

A pesquisa utilizou toda população de pacientes atendidos na instituição no período de julho de 2015 a julho de 2019, com os seguintes critérios de inclusão: pacientes com idade entre zero e onze anos, onze meses e trinta dias (a determinação da idade foi baseada na classificação do estatuto da criança e do adolescente brasileiro); ambos os sexos; internados na enfermaria pediátrica ou unidade de terapia intensiva pediátricas; ter o resultado de pelo menos um exame laboratorial durante o período de internação. $\mathrm{Na}$ instituição em estudo no período determinado, foram atendidas 371 crianças vítimas de queimaduras do ano de 2015 a 2019, dessas 105 não atendia os critérios de inclusão e exclusão, 03 foram aplicados o teste piloto, configurando a amostra final em 263 pacientes.

A coleta de dados ocorreu de agosto a novembro de 2020, por meio da análise de prontuários, que na instituição estudada dispõe de $100 \%$ dos seus prontuários em sistema eletrônico. A coleta foi norteada por um instrumento semi-estruturado com questões sócio-demográficas, clínicas, laboratoriais e relacionadas à internação.

As questões Sociodemográficas: (idade, sexo e procedência); Clínicas: agente causador da queimadura (escaldadura, térmica, química, elétrica e mecânica), profundidade da queimadura (primeiro, segundo e terceiro grau), Superfície Corporal Queimada (SCQ), classificação da extensão da queimadura (pequeno, médio e grande queimado), sítio de localização da queimadura. Internação: data de admissão, tempo de internação, número de óbitos e número de reinternações. Clínico-laboratorial: hemograma, eletrólitos (sódio, potássio, magnésio, cloretos, fosfato e cálcio), proteína $C$ reativa (PCR), albumina, coagulograma: Tempo de atividade de Protrombina (TAP) e Tempo de Atividade de Tromboplastina Ativada (TTPa), ureia, creatinina e cultura/biópsias de agentes infecciosos.

Foram considerados os seguintes valores de referência para os exames clínicos-laboratoriais, de acordo com o laboratório de análises clínicas do centro estudado: hemácias: 3,9-5,3 milhões/ $\mu \mathrm{L}$; hemoglobina: 11,5-

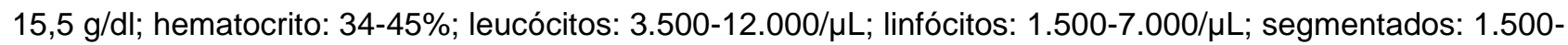

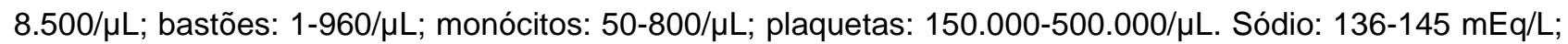
potássio: 3,5-5,1 mEq/L; magnésio: 1,8-2,6 mEq/L; cloretos: $101-111 \mathrm{mEq} / \mathrm{L}$; fósforo: 2,5-4,5 mEq/L; calcio total: 8,8-10,8 mg/dl. PCR: 0,1-5,0 mg/dl; albumina: 3,5-5,2 mg/dl; TAP: 9,3-13,3s; RNI: 0,8-1,2; TTPA: 25,136,5s; uréia: 10,8-38,4 mg/dl; creatinina: 0,4-1,2 mg/dl.

Foi realizada análise descritiva, apresentada em frequências absolutas e relativas para as variáveis categóricas. Para as variáveis contínuas, utilizou-se média e desvio padrão da média. Foi realizado teste de Shapiro Wilk para averiguar a normalidade dos dados e a partir disto, foi aplicada estatística não paramétrica para comparação das variáveis contínuas, especificamente o teste de Kruskal-Wallis. Mediante significância deste teste foi aplicado teste de diferenciação de Nemenyi. Foi aplicado ainda o teste Exato de Fisher para examinar a homogeneidade dos grupos em relação às proporções e o teste de Mann-Whitney para verificar a heterogeneidade de amostras ordinais. O nível de significância utilizado para todos os testes foi de $5 \%$.

Esse estudo foi aprovado pelo Comitê de Ética em Pesquisa (CEP) do Centro de Excelência em Ensino, Pesquisa e Projetos "Leide Das Neves Ferreira" (CEEPP) sob número de parecer: 4.141.012. Por se tratar de um estudo de dados secundários, foi realizada a isenção da assinatura do termo de consentimento livre e esclarecido e foi assinado ainda o termo de compromisso para utilização e manuseio de dados. A pesquisa seguiu as normas e diretrizes que regulamentam as pesquisas que envolvem seres humanos e as determinações contidas na Resolução 466/2012, do Conselho Nacional de Saúde. 


\section{RESULTADOS}

Foram analisados 263 prontuários de pacientes pediátricos, vítimas de queimaduras, com uma média de idade de 3,7 anos, sendo 52,4\% (138/263) provenientes da cidade em estudo e região metropolitana, 46,9\% (123/263) referenciados do interior do estado e duas crianças $(0,7 \%)$ provenientes de outros estados. Foi encontrado uma população homogênea referente ao mês de queimadura, com um pico de prevalência em junho (Figura 1).

Figura 1 - Crianças vítimas de queimaduras distribuídas conforme o mês de admissão.

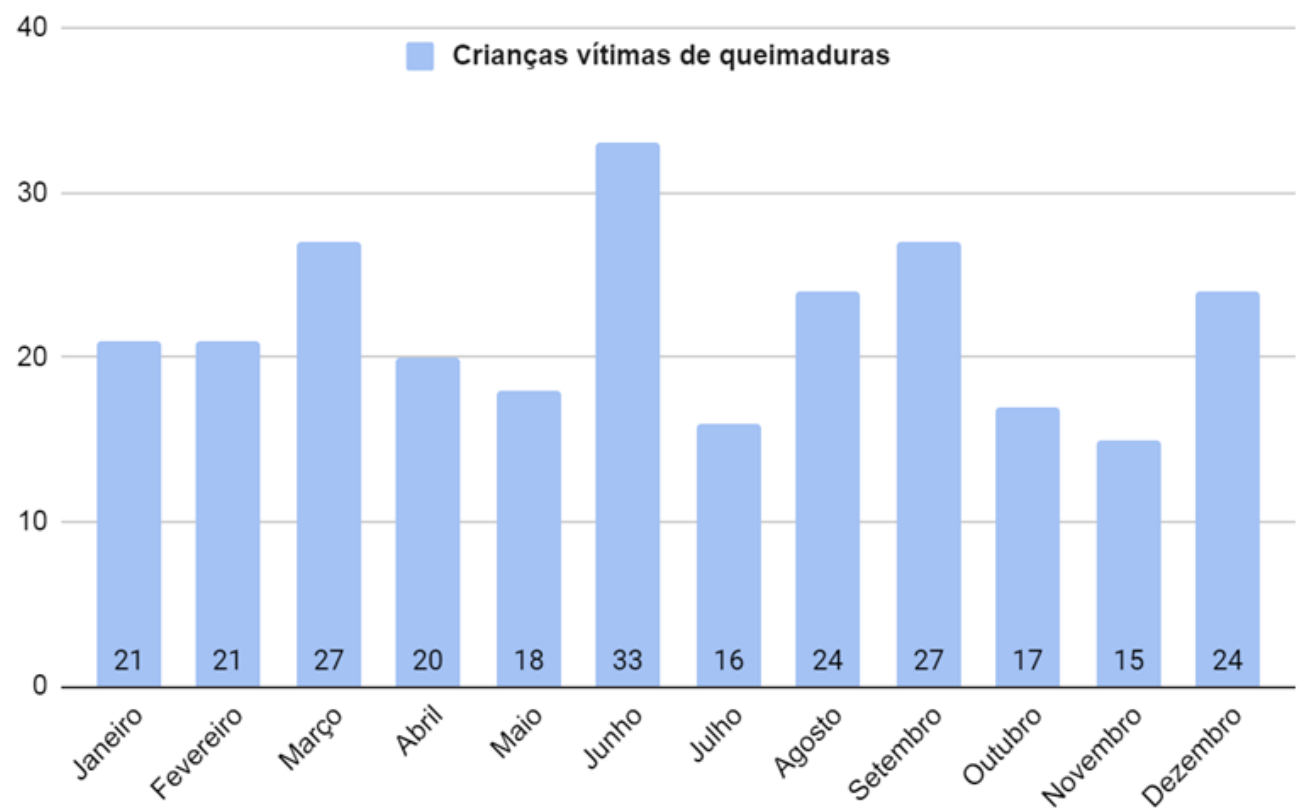

Fonte: Colares CMP, et al., 2021.

A principal etiologia encontrada nos pacientes vítimas de queimadura, em ambos os sexos, foi a escaldadura, seguido pela chama direta (Tabela 1).

Tabela 1 - Etiologia da queimadura de acordo com o sexo.

\begin{tabular}{|c|c|c|c|c|c|}
\hline \multirow{3}{*}{ Etiologia da queimadura } & \multicolumn{4}{|c|}{ Sexo } & \multirow{3}{*}{$p$-valor } \\
\hline & \multicolumn{2}{|c|}{ Feminino } & \multicolumn{2}{|c|}{ Masculino } & \\
\hline & $\mathbf{n}$ & $\%$ & $\mathbf{n}$ & $\%$ & \\
\hline Escaldadura & 60 & 60,0 & 88 & 53,9 & \\
\hline Chama direta & 25 & 25,0 & 46 & 28,2 & \\
\hline Choque elétrico & 7 & 7,0 & 12 & 7,3 & 0026 \\
\hline Térmica & 5 & 5,0 & 10 & 6,1 & $0,0<0$ \\
\hline Abrasão & 3 & 3,0 & 5 & 3,0 & \\
\hline Química & 0 & 0 & 2 & 1,2 & \\
\hline
\end{tabular}

Legenda: ${ }^{*} p$-valor obtido pelo Teste exato de Fisher, considerando 5\% para nível de significância.

Fonte: Colares CMP, et al., 2021.

Foi frequente a presença de queimaduras em mais de um sítio, prevalecendo queimaduras em região de tronco (162 - 61,6\%), seguido por membro superior esquerdo (108 - 41,0\%), membro superior direito (99$37,6 \%)$, face $(90-34,2 \%)$, membro inferior direito $(84-31,9 \%)$, membro inferior esquerdo $(83-31,5 \%)$, pescoço $(39-14,8 \%)$, períneo $(23-8,7 \%)$ e genitália (14 - 5,3\%). Em relação a profundidade da queimadura, o tipo mais frequente foi o de $2^{\circ}$ grau em $93,9 \%$ (247/263) da população.

O tempo de internação médio em enfermaria foi de 14,3 dias e o tempo de internação médio em Unidade de Terapia Intensiva Pediátrica (UTIP) de 15,7 dias, sendo que 13,69\% (36/263) necessitaram de internação 
na UTIP. A taxa de óbito foi zero nesta população no período avaliado. Os marcadores laboratoriais evidenciados durante a internação das crianças foram correlacionados com a extensão da queimadura. Evidenciou-se que os grandes queimados apresentaram maiores valores de hemácias, hemoglobina e hematócrito na admissão, porém com quedas abruptas no $5^{\circ}$ dia de internação $(p<0,05$ para a variável hemácias) (Tabela 2).

Tabela 2 - Dinâmica do hemograma na admissão, no $5^{\circ}, 10^{\circ}$ e $15^{\circ}$ dias de internação de acordo com a extensão da queimadura.

\begin{tabular}{|c|c|c|c|c|c|c|c|c|}
\hline \multirow{3}{*}{ Variável } & \multicolumn{8}{|c|}{ Classificação da queimadura } \\
\hline & \multicolumn{4}{|c|}{ Médio Queimado(n=152) } & \multicolumn{4}{|c|}{ Grande Queimado(n=103) } \\
\hline & Dia 0 & Dia 5 & Dia 10 & Dia 15 & Dia 0 & Dia 5 & Dia 10 & Dia 15 \\
\hline Hemácias* & 4,6 & & 3,7 & 4,1 & 4,9 & $3,6 b$ & 3,7 & 3,4 \\
\hline & & & 9 & & 12 & 9 & 10,1 & 9,5 \\
\hline Hem & 36,0 & 3 & 28,9 & 3 & 3 & 30,0 & 31,0 & 28,9 \\
\hline & & & & & & & & \\
\hline & 3 & & 5. & & & & & 3.536 \\
\hline Bas & 384 & 1.2 & $553 a$ & $245 a a$ & 622 & 1.077 & $1.675 b$ & $1.906 \mathrm{bb}$ \\
\hline ados* & 14.497 & 9.421 & $8.030 \mathrm{a}$ & 7.148 & 9.600 & 5.238 & $9.943 b$ & 10.450 \\
\hline & 779 & & 99 & 7 & 9 & & & 1.111 \\
\hline Plaquetas & 353.753 & 397.000 & 559.250 & 640.000 & 346.753 & 318.421 & 474.200 & 618.800 \\
\hline
\end{tabular}

Legenda: ${ }^{*} p$-valor $<0,05$ pelo teste de Kruskal Wallis. Letras minúsculas ladeadas das médias representam diferença significativa pelo teste de Nemenyi (grupo "a" com grupo "b" e grupo "aa" com grupo "bb"), todos com $5 \%$ de nível de significância.

Fonte: Colares CMP, et al., 2021.

Observa-se ainda recuperação dos níveis da série vermelha no $10^{\circ}$ dia de internação, porém com tendência à nova queda no 15 dia nos grandes queimados, evidenciando uma anemia prolongada durante a


demonstrando uma tendência a um desvio à esquerda ( $>10 \%$ de bastões em relação aos segmentados) e leucocitose no $10^{\circ}$ e $15^{\circ}$ dias de internação de ambos, médios e grandes queimados. A trombocitose também foi observada no $15^{\circ}$ dia de internação de ambos os grupos.

Conforme rotina de solicitação de exames, os eletrólitos também foram seriados durante a internação e correlacionados com os grupos quanto à extensão da queimadura, de acordo com os dias de internação. Os resultados apontam para distúrbios eletrolíticos em diversos pontos da internação. As relações estatísticas foram encontradas nos valores de sódio na admissão. Houve hiponatremia e hipocloremia severa observados no $15^{\circ}$ dia de internação de grandes queimados. As crianças grandes queimadas apresentaram menores valores de cálcio total desde a admissão, sendo evidenciado ainda hipocalcemia no 15 dia de internação (Tabela 3).

Tabela 3 - Dinâmica dos eletrólitos na admissão, nos 5ํ, $10^{\circ}$ e $15^{\circ}$ dias de internação de crianças vítimas de queimaduras.

\begin{tabular}{|c|c|c|c|c|c|c|c|c|c|c|c|c|}
\hline \multirow{3}{*}{ Variável } & \multicolumn{12}{|c|}{ Classificação da queimadura } \\
\hline & \multicolumn{4}{|c|}{ Pequeno queimado(n=8) } & \multicolumn{4}{|c|}{ Médio queimado(n=152) } & \multicolumn{4}{|c|}{ Grande queimado(n=103) } \\
\hline & Dia 0 & $\begin{array}{c}\text { Dia } \\
5 \\
\end{array}$ & $\begin{array}{c}\text { Dia } \\
10 \\
\end{array}$ & $\begin{array}{c}\text { Dia } \\
15 \\
\end{array}$ & Dia 0 & Dia 5 & $\begin{array}{c}\text { Dia } \\
10 \\
\end{array}$ & $\begin{array}{c}\text { Dia } \\
15 \\
\end{array}$ & Dia 0 & Dia 5 & $\begin{array}{c}\text { Dia } \\
10 \\
\end{array}$ & Dia 15 \\
\hline Sódio* & $137,0 \mathrm{ab}$ & - & - & - & $137,4 a$ & 134,7 & 136,8 & 138,0 & $136,3 b$ & 135,0 & 136,2 & 132,5 \\
\hline Potássio & 4,1 & - & - & - & 4,4 & 4,1 & 3,7 & 4,7 & 4,4 & 3,7 & 4,0 & 4,4 \\
\hline Cloretos & 111,0 & - & - & - & 104,8 & 103,5 & 101,0 & - & 103,9 & 100,0 & 103,2 & 95,7 \\
\hline Magnésio* & - & - & - & - & $2,1 \mathrm{a}$ & 2,3aa & 2,1 & - & $1,9 b$ & $1,9 b b$ & 2,0 & - \\
\hline Fósforo & - & - & - & - & 5,1 & 5,8 & - & - & 5,6 & - & 4,0 & - \\
\hline $\begin{array}{l}\text { Cálcio } \\
\text { total }^{*}\end{array}$ & - & - & - & - & $9,6 a$ & 9,8aa & 9,6 & - & $9,0 b$ & $8,8 \mathrm{bb}$ & 8,8 & 8,6 \\
\hline
\end{tabular}

Legenda: ${ }^{*} p$-valor $<0,05$ pelo teste de Kruskal Wallis. Letras minúsculas ladeadas das médias representam diferença significativa pelo teste de Nemenyi (grupo "a" com grupo "b" e grupo "aa" com grupo "bb"), todos com $5 \%$ de nível de significância.

Fonte: Colares CMP, et al., 2021. 
Outros marcadores laboratoriais foram analisados de acordo com a classificação da extensão da queimadura, a hipoalbuminemia foi presente nos grandes queimados desde a admissão ( $p<0,05$ na admissão). Evidenciou-se ainda hipocreatinemia em diversas fases da internação hospitalar e em todos os grupos analisados. O coagulograma sugeriu risco de hemorragia desde a admissão, com valores elevados no tempo de protrombina (TAP) $(p<0,05)$ (Tabela 4).

Tabela 4 - Marcadores laboratoriais na admissão, nos $5^{\circ}$, 10 e $15^{\circ}$ dias de internação de acordo com a extensão da queimadura.

\begin{tabular}{|c|c|c|c|c|c|c|c|c|c|c|c|c|}
\hline \multirow{3}{*}{ Variável } & \multicolumn{12}{|c|}{ Classificação da queimadura } \\
\hline & \multicolumn{4}{|c|}{ Pequeno queimado(n=8) } & \multicolumn{4}{|c|}{ Médio queimado(n=152) } & \multicolumn{4}{|c|}{ Grande queimado(n=103) } \\
\hline & Dia 0 & $\begin{array}{c}\text { Dia } \\
5\end{array}$ & $\begin{array}{c}\text { Dia } \\
10\end{array}$ & $\begin{array}{c}\text { Dia } \\
15\end{array}$ & Dia 0 & Dia 5 & Dia 10 & $\begin{array}{c}\text { Dia } \\
15\end{array}$ & Dia 0 & Dia 5 & Dia 10 & $\begin{array}{c}\text { Dia } \\
15\end{array}$ \\
\hline Proteína C & & & & & & & & & & & & \\
\hline $\begin{array}{l}\text { Reativa } \\
(\mathrm{PCR})^{\star}\end{array}$ & 2,0 & - & - & - & 10,9 & $34,3 a$ & 82,8 & 8,3 & 17,1 & $125,9 b$ & 62,8 & 89,1 \\
\hline Albumina* & $4,0 a b$ & - & - & - & $4,1 \mathrm{a}$ & 3,0 & 3,3 & 4,1 & $3,6 b$ & 3,0 & 3,0 & 2,4 \\
\hline Ureia & 17,1 & - & - & - & 21,6 & 14,2 & 8,7 & - & 24,6 & 19,2 & 29,1 & 34,6 \\
\hline Creatinina & 0,2 & - & - & - & 0,3 & 0,3 & 0,2 & - & 0,5 & 0,3 & 0,3 & 0,3 \\
\hline TAP* $^{*}$ & - & - & - & - & $13,9 a$ & 11,3 & $12,5 \mathrm{aa}$ & - & $15,0 \mathrm{~b}$ & 13,8 & $14,5 \mathrm{bb}$ & 13,4 \\
\hline $\mathrm{RNI}^{*}$ & - & - & - & - & $1,10 a$ & 0,9 & 1,0 & - & $1,18 b$ & 1,0 & 1,1 & 1,0 \\
\hline TTPA & - & - & - & - & 30,5 & 18,2 & 24,7 & - & 32,2 & 30,9 & 29,3 & 26,7 \\
\hline
\end{tabular}

Legenda: ${ }^{*} \boldsymbol{p}$-valor $<\mathbf{0 , 0 5}$ pelo teste de Kruskal Wallis. Letras minúsculas ladeadas das médias representam diferença significativa pelo teste de Nemenyi (grupo "a" com grupo "b" e grupo "aa" com grupo "bb", todos com $5 \%$ de nível de significância.

Fonte: Colares CMP, et al., 2021.

A proteína $C$ reativa (PCR) apresentou uma dinâmica que acompanha a extensão da queimadura, sendo assim, grandes queimados apresentaram valores maiores de PCR desde a admissão ( $p<0,05$ no $5^{\circ}$ dia de internação), com queda no $10^{\circ}$ dia e novo aumento em torno do $15^{\circ}$ dia de internação, conforme apresentado na Tabela 4.

\section{DISCUSSÃO}

A faixa etária predominante de 3,7 anos foi semelhante em estudo de Barcellos LG, et al. (2018), uma Unidade de Terapia Intensiva Pediátrica de Porto Alegre e em estudo de Moraes OS, et al. (2014), conduzido num Centro de Tratamento de Queimados de um hospital de Londrina entretanto, inferior em relação ao estudo de Millian LC, et al. (2012), conduzido em São Paulo, onde foi prevalente a média de 5,2 anos de idade.

Além disso, ser do sexo masculino e apresentar a escaldadura como etiologia de queimadura foram fatores igualmente prevalentes no presente estudo e nos estudos nacionais e internacionais pois são aspectos bem consolidados na literatura no que diz respeito às características das queimaduras na população pediátrica (BARCELLOS LG, et al., 2018; LEE CJ, et al., 2016; MORAES PS, et al., 2014; FERNANDES FMF, et al., 2012; MILLIAN LC, et al., 2012).

A predominância do sexo masculino pode ser esclarecido pela distinção de atividade desenvolvida em cada sexo, visto que na visão cultural o menino conquista mais liberdade que a menina, de forma que crianças do sexo masculino comumente dispõe de maior entusiasmo a entretenimentos perigosos, à medida que as do sexo oposto desenvolvem atividades mais leves, as primeiras com menor vigilância direta dos adultos e maior tempo de exposição a eventos que antecipam acidentes (FERNANDES FMF, et al., 2012; SIQUEIRA SMC, et al., 2017).

Barcellos LG et al. (2018), abordam que apesar da escaldadura ser mais prevalente, queimaduras por chama direta e por choque elétrico apresentam maior morbimortalidade, fator que não pôde ser avaliado neste estudo, pois a mortalidade foi zero no período avaliado. Não houve diferença estatisticamente significativa 
quando relacionado o sexo com a etiologia da queimadura, apesar do sexo masculino estar mais exposto a todos os mecanismos de queimaduras avaliados e habitualmente ser uma fase do desenvolvimento neuropsicomotor da criança marcado por animação, descoordenação e necessidade de exploração de objetos e do ambiente em que vivem (FERNANDES FMF, et al., 2012).

O estudo de Correia DS, et al. (2019), reforça que a criança possui uma curiosidade normal, por estar passando por um momento de descoberta e conhecimento do cotidiano, o que demostra a relevância de maior atenção por parte dos responsáveis, que deve ser duplicada devido à ausência de noção em relação ao perigo associada às crianças nessa idade.

O mês com maior prevalência de queimaduras foi em junho, caracterizado por ser um mês festivo no Brasil com as festas juninas, onde há um maior uso de balões e fogueiras, predispondo à acidentes com chama direta, tal como maior preparo de alimentos quentes, facilitando os acidentes por escaldadura (MORAES PS, et al., 2014).

Os sítios de lesões mais prevalentes foram o tronco e os membros superiores, concordante com estudo no norte do Brasil, fator que provavelmente está relacionado com as escaldaduras, uma vez que são frequentes os acidentes ao puxar o cabo da panela e serem queimadas por líquidos superaquecidos (SANTANA ME, et al., 2018).

Crianças classificadas como médios queimados foram mais prevalentes no presente estudo com $57,8 \%$ da população, corroborando com dados da pesquisa de Barcellos LG et al. (2018), que relataram $60 \%$ da amostra de crianças com este mesmo perfil e $39,9 \%$ de grandes queimados, corroborando também com o presente estudo, onde $39,2 \%$ da população foi classificada como grande queimado. A literatura demonstra significativa associação entre superfície corporal queimada e mortalidade, evidenciando que quanto maior a extensão da queimadura, maior o risco de óbito por essas crianças (BARCELLOS LG, et al., 2018; GREENHALGH DG, 2019).

Entende-se que a profundidade da lesão por queimaduras está associada à temperatura e à duração do contato do agente etiológico com a pele. Compreende-se que as crianças possuem a pele mais frágil, por isso, queimaduras leves podem converter-se para graves rapidamente (CORREIA DS, et al., 2019).

O tempo de internação médio em enfermaria esteve dentro da faixa de estudos nacionais com uma população estudada semelhante com média de internação de 14 dias e superior a estudos internacionais, onde a média de permanência em enfermaria é de 10 dias (MORAES PS, et al., 2014). O tempo de internação médio em UTIP do presente estudo esteve na mesma faixa de estudo conduzido em instituições dos EUA, sendo uma média de internação de 15 dias (LEE CJ, et al., 2016).

Os exames clínico-laboratoriais fornecem parâmetros fundamentais acerca do estado de saúde das crianças vítimas de queimaduras. No presente estudo valores de hemácias, hemoglobina e hematócrito foram menores nas crianças grandes queimadas e apresentaram progressivas quedas durante a internação, evidenciando um processo de consumo de células vermelhas devido ao estado de hipermetabolismo, associado ainda à perda sanguínea e perdas para o $3^{\circ}$ espaço durante toda a internação (OSUKA AA, et al., 2019).

Diversos estudos internacionais em adultos demonstram que os níveis de plaquetas possuem quedas abruptas por volta do $3^{\circ}$ dia de internação, fator que provavelmente está relacionado ao consumo exacerbado do organismo pela ativação da cascata de coagulação relacionado às lesões, com posterior elevação a níveis até duas vezes maiores que os normais no $10^{\circ}$ ao $15^{\circ}$ dia de internação, pelo trabalho de compensação exercido pela medula óssea (CATO LD, et al., 2018; MARCK RE, et al., 2013; OSUKA AA, et al., 2019).

No presente estudo não foram observadas grandes reduções dos níveis de plaquetas no $3^{\circ}$ ao $5^{\circ}$ dia de internação, fator que pode estar relacionado à maior capacidade de produção de células das crianças, em comparação com a população adulta. A trombocitopenia ainda está relacionada à maior mortalidade na população pediátrica e como preditor de desenvolvimento de sepse, parâmetro que é fundamental no diagnóstico precoce da disfunção orgânica (CATO LD, et al., 2018; MANNING J, 2018; MARCK RE, et al., 2013). 
Os distúrbios eletrolíticos foram mais comuns a partir do $10^{\circ}$ dia de internação, entretanto, crianças grandes queimadas apresentaram menores valores de sódio, potássio, cloretos, magnésio e cálcio total desde a admissão, valores que foram estatisticamente significantes. A ressuscitação volêmica inicial e o uso de soluções de manutenção isotônicas são fundamentais para garantir a estabilidade hemodinâmica inicial, tal como a prevenção de hiponatremia durante a internação (FELD LG, et al., 2018). Além disso, a redução de valores de cálcio sérico em pacientes queimados pode estar relacionada ao processo inflamatório prolongado, portanto a, manutenção de valores normais de cálcio podem atenuar a intensidade da resposta inflamatória ou reduzir sua duração (KLEIN G, et al., 2017).

A Proteína C-Reativa (PCR), um dos principais marcadores de inflamação esteve relacionado à SCQ da queimadura no presente estudo. Quanto maior a SCQ, maiores foram os valores de PCR. Naturalmente, o processo inflamatório da queimadura é constante, entretanto, novas elevações nos valores de PCR durante a internação estão associadas a focos infecciosos e atuam como preditores de mortalidade em crianças queimadas (ROSANOVA MT, et al., 2015).

A albumina, durante anos esteve associada ao estado nutricional do indivíduo (ISHIDA S, et al., 2014). No presente estudo, crianças grandes queimadas apresentaram valores abaixo dos níveis de normalidade desde a admissão, fator que corrobora com o fato de que 3,4\% da população do estudo necessitou de reposição de albumina humana. Entretanto, novos estudos demonstram que valores de albumina estão fortemente associados ao processo inflamatório, podendo estar em concentrações reduzidas independente do estado nutricional da criança, atuando ainda como preditor da gravidade do trauma e de mortalidade, ao invés de somente status nutricional (ISHIDA S, et al., 2014).

De modo geral, em crianças a queimadura é um considerada um trauma grave, tendo como repercussões a lesão física e suas complicações, sendo causadora de um tratamento demorado, doloroso e altamente especializado, geralmente levando a infecções, sequelas físicas e psicológicas, estéticas e impactos socioeconômicos. Perante a gravidade do problema e considerando a especificidade do tratamento, tornase essencial que o profissional da saúde disponha de habilidade em lidar com este paciente, conheça sobre as respostas fisiopatológicas e as alterações laboratoriais (BATISTA LTO, et al., 2011; MORAIS JUNIOR, et al., 2018).

\section{CONCLUSÃO}

A média de idade das crianças do estudo foi de 3,7 anos, predominantemente vítimas de escaldaduras em tronco e em membros superiores, sendo mais frequente, médio e grandes queimados. Exames laboratoriais indicam relação estatisticamente significativa entre extensão da queimadura e menores valores na série vermelha, leucocitose com tendência a desvio a esquerda, distúrbios eletrolíticos, baixos valores de albumina e altos valores de mediadores inflamatórios como a Proteína C-Reativa. O perfil clínicoepidemiológico destas crianças possui relação estatisticamente significativa com os exames laboratoriais, mapeando a internação destas crianças e auxiliando profissionais da linha de frente a identificar precocemente complicações que agravam o quadro destas crianças. As limitações deste estudo estão relacionadas ao trabalho com dados retrospectivos e de prontuários eletrônicos, pois dependem de corretas avaliações e descrições por parte dos profissionais envolvidos no processo, além de se tratar de um único centro de trauma.

\section{REFERÊNCIAS}

1. BARCELLOS LG, et al. Características e evolução de pacientes queimados admitidos em unidades de terapia intensiva pediátrica. Rev Bras Ter Intensiva, 2018; 30(3): 333-37.

2. BATISTA LTO, et al. Características clínicas e diagnósticos de enfermagem em crianças vítimas de queimaduras. Rev. Rene, 2011; 12(1): 158-65.

3. CATO LD, et al. Platelet count: A predictor of sepsis and mortality in severe burns. Burns, 2018; 44(2): $288-297$.

4. CORREIA DS, et al. Perfil de crianças e adolescentes internados no centro de terapia de queimados. Rev enferm UFPE on line, 2019; 13(5): 1361-9. 
5. DUTRA JPS, et al. Estudo clínico-epidemiológico de pacientes queimados internados em uma unidade de terapia intensiva em Goiás. Rev Bras Queimaduras, 2017; 16(2): 87-93.

6. FELD LG, et al. Clinical Practice Guideline: Maintenance Intravenous Fluids in Children. Pedriatrics, $2018 ; 142$ (6).

7. FERNANDES FMF, et al. Queimaduras em crianças e adolescentes: caracterização clínica e epidemiológica. Rev Gaúcha Enferm, 2012; 33 (4): 133-41.

8. GREENHALGH DG. Management of burns. N Engl J Med, 2019; 380( 24).

9. ISHIDA S, et al. Serum albumin levels correlate with inflammation rather than nutrition supply in burns patients: a retrospective study. The Journal of Medical Investigation, 2014; 61 (3-4): 361-368.

10. KHONGWAR D, et al. Clinical study of burn patients requiring admission: A single center experience at North Eastern Indira Gandhi Regional Institute of Health and Medical Sciences. J Family Med Prim Care, 2016; 5 (2): 444-448.

11. KLEIN G, et al. Calcemic response to burns differs between adults and children: A review of the literature. Osteoporosis and Sarcopenia, 2017; 3: 170-173.

12. KUO G, et al. Hyper phosphatemia is associated with high mortality in severe burns. PLoS ONE, 2018; 13(1).

13. LEE CJ, et al. Pediatric burns: a single institution retrospective review of incidence, etiology, and outcomes in 2273 burn patients (1995-2013). Journal of Burn Care Research, 2016; 37 (6): 579-85.

14. MANNING J. Sepsis in the Burn Patient. Crit Care Nurs Clin N Am. 2018; 30(3): 423-430.

15. MARCK RE, et al. Time course of thrombocytes in burn patients and its predictive value for outcome. Burns, 2013; 39: 714-722.

16. MILLAN LC, et al. Estudo epidemiológico de queimaduras em crianças atendidas em hospital terciário na cidade de São Paulo. Rev Bras Cir Plást, 2012; 27 (4): 611-5.

17. MORAES PS, et al. Perfil das internações de crianças em um centro de tratamento para queimados. Rev Eletr Enf [Internet], 2014; 16 (2): 598-603.

18. MORAIS JÚNIOR SLA, et al. Diagnósticos de Enfermagem à Criança com Queimadura no Pronto-Socorro Infantil: uma revisão integrativa. Revista Enfermagem Atual In Derme, 2018; 84 (22).

19. OSUKA A, et al. Natural kinetics of blood cells following major burn: impact of early decreases in White blood cells and platelets as prognostic markers of mortality. Burns. 2019.

20. SANTANA ME, et al. Clinical and epidemiological profile of children with burns in a reference hospital. Rev Enferm UFPI; 2018, 7 (2): 23-7.

21. SILVA PKE, et al. Caracterização das crianças vítimas de queimaduras em hospital de referência na região Amazônica. Rev Bras Queimaduras; 2015; 14(3): 218-223.

22. SIQUEIRA SMC, et al. Internações e óbitos de crianças e adolescentes brasileiros vítimas de queimaduras por fogos de artifício. Revista Brasileira de Queimaduras, 2017; 16 (2):68-75.

23. STROBEL AM, FEY R. Emergency care of pediatric burns. Emerg Med Clin Nam; 2018, 36: 441-58.

24. SU L, et al. Emerging progresson the mechanism and technology in wound repair. Biomedicine \& Pharmacotherapy; $2019,117$.

25. ROSANOVA MT, et al. Evaluación del valor de la proteína $C$ reactiva y de la procalcitonina em la predicción de infección y mortalidade em los niños quemados. Arch Argent Pediatr; 2015, 113 (1): 36-41.

26. TIRYAKI C, HAKSAL MC. Comparison of clinical finding in adult and paediatric burn victims. Niger J Clin Pract; 2019 , 22: $642-7$. 